\title{
The Collateral Damage of COVID-19
}

Jonika Tannous, PhD, and Farhaan S. Vahidy, PhD, MBBS, MPH

Neurology ${ }^{\circledR}$ 2022;98:219-220. doi:10.1212/WNL.0000000000013196

The SARS-CoV-2 virus has infected $>250$ million people worldwide, including 46 million in the United States. This represents approximately $3.2 \%$ of the global and $14 \%$ of the US population. Because of major disruptions to medical systems worldwide, the effect of the COVID-19 pandemic on health goes beyond the number of directly infected people. For example, from the earliest days of the pandemic, significant disruptions in acute cerebrovascular evaluations were observed, ${ }^{1}$ followed by consistent reports of uncharacteristic declines in acute stroke admissions to hospitals in the United States and other countries. ${ }^{2}$ As the COVID-19 pandemic waves hit various regions of the globe, the health care systems pivoted to direct all available resources towards acute in-hospital critical care of infected patients. Although necessary, this shift came at the expense of preventive and chronic care management. The emerging pandemic therefore constituted a perfect storm for older adults and for those with the most need for chronic risk and disease management. On one hand, they were highly susceptible to infection and poor COVID-19 outcomes; and on the other, disruptions in regular care made them more vulnerable to incident or worsening chronic disease outcomes. Until recently, the effect of the pandemic on population health strategies for primary and secondary stroke prevention that are critical to reducing cerebrovascular disease burden has not been well studied.

In this issue of Neurology ${ }^{\circledR}$, Velek and colleagues ${ }^{3}$ published a study that starts to fill this gap by highlighting the inadvertent effects of the COVID-19 pandemic on the population-wide burden of cerebrovascular disease. Using electronic health records from $18 \%$ of the general practices (GPs) in the Rotterdam region in the Netherlands, the authors found that new diagnoses of stroke and TIA had declined by $29 \%$ and $37 \%$, respectively, during the first pandemic wave (March-May 2020) compared to prepandemic derived expected counts. These declines were accompanied by similar or greater reductions in new diagnoses of cerebrovascular risk factors (hypertension, diabetes, lipid disorders, and atrial fibrillation). Significant declines in the number of overall cerebrovascular and cardiovascular GP consultations were also noted.

With a focus on new diagnoses, this study did not evaluate the pandemic's effect on primary care among those with preexisting risk factors or prior cerebrovascular events. It has been demonstrated that the widespread postponement of elective procedures and visits, coupled with anxiety about COVID-19 exposure, caused larger disruptions in care for people with chronic illnesses. ${ }^{4}$ Velek et al. ${ }^{3}$ report age and sex differences, with people over 65 and women experiencing the largest declines in GP encounters, but they did not evaluate how social determinants of health $(\mathrm{SDOH})$ may differentially affect GP consultations and new diagnoses. This could be due to relative homogeneity of the study population or unavailability of SDOH metrics. Utilization is tightly linked to health care system factors (including insurance) and therefore wider generalizability of findings to other countries is somewhat limited. However, in a broader context, the findings in the Velek et al. ${ }^{3}$ study are congruent with other reports, and the disruption may be greater in settings with limited access to free or low-cost care and smaller networks of GP providers. ${ }^{5}$ In the United States, for instance, primary health care visits in April 2020 were down $51 \%$ compared with a year prior, and despite a rebound with the easing of COVID-19 restrictions, the cumulative adult primary care visits in 2020 remained 10\% lower than baseline. ${ }^{6}$
Correspondence

Dr. Vahidy

fvahidy@

houstonmethodist.org

RELATED ARTICLE

Research Article

Changes in the Diagnosis

of Stroke and

Cardiovascular Conditions

in Primary Care During the

First 2 COVID-19 Waves

in the Netherlands

Page 223

\section{MORE ONLINE}

\section{COVID-19 Resources}

For the latest articles, invited commentaries, and blogs from physicians around the world NPub.org/COVID19 
It is also important to note that unlike diagnoses for stroke or TIA, the authors did not find a similar reduction for myocardial infarction or angina pectoris. Avoidance or delay in seeking stroke care may be attributed to relative lack of awareness about cerebrovascular disease symptoms, particularly mild or transient ones. Therefore, an exigent call to action for continued emphasis on stroke education is embedded in the study findings.

If we are to avoid public health crises in the future and mitigate the collateral damage of global catastrophes, particularly for the most vulnerable, it is imperative that we invest in sustainable access to primary care through fostering dynamic population health management systems. To engage and care for patients who are uninsured or underinsured, including disadvantaged populations, the coverage of community health clinics must be expanded. This may require launching or expanding telehealth practices and embracing tools that offload aspects of patient monitoring and administrative tasks using technologies, such as wearables, patient portals, and e-health questionnaires. While telehealth services saw rapid growth at the onset of the COVID-19 pandemic, the World Health Organization reports that uptake of telehealth is largely stratified by wealth gaps, and further targeted investment is necessary for equitable implementation. ${ }^{7,8}$ To ensure that older adults or underserved populations are not left behind in the transition to a more tech-forward health care system, major expansion of free or affordable broadband access is needed. Reaching these populations may also require radical growth of at-home health options that allow for management in an environment that minimizes risk of disease transmission. Lastly, the worsening shortage of primary care professionals and the disparate distribution of physicians poses a challenge to broadening GP access. Solutions range from increasing the autonomy and responsibilities of nurse practitioners, physician assistants, and medical assistants to providing financial incentives for potential primary care residents, such as scholarships and loan forgiveness. 9,10 These critical investments in the advancement and expansion of our primary health care system would not only ensure continuity of necessary care during public health emergencies, but will also help mitigate underlying inequities in postpandemic times.

The true consequences of pandemic-driven disruptions in primary health care for patients with or at risk of cerebrovascular disease are yet to be fully quantified; however, if continued, the historic neglect of our population health management systems will only exacerbate the primary catastrophe of pandemic-like events.

\section{Study Funding}

The authors report no targeted funding.

\section{Disclosure}

None. Go to Neurology.org/N for full disclosures.

\section{References}

1. Kansagra AP, Goyal MS, Hamilton S, Albers GW. Collateral effect of covid-19 on stroke evaluation in the United States. N Engl J Med. 2020;383(4):400-401.

2. Liu R, Zhao J, Fisher M. The global impact of COVID-19 on acute stroke care. CNS Neurosci Ther. 2020;26(10):1103-1105.

3. Velek P, Splinter MJ, Ikram MK, et al. Changes in the diagnosis of stroke and cardiovascular conditions in primary care during the first 2 COVID-19 waves in the Netherlands. Neurology. 2022;98(6):e564-e572.

4. Kendzerska T, Zhu DT, Gershon AS, et al. The effects of the health system response to the COVID-19 pandemic on chronic disease management: a narrative review. Risk Manag Healthc Pol. 2021;14:575-584.

5. Williams R, Jenkins DA, Ashcroft DM, et al. Diagnosis of physical and mental health conditions in primary care during the COVID-19 pandemic: a retrospective cohort study. Lancet Public Health. 2020;5(10):e543-e550.

6. Mehrotra A, et al. The Impact of COVID-19 on Outpatient Visits in 2020: Visits Remained Stable, Despite a Late Surge in Cases. Available at: commonwealthfund.org/. doi: $10.26099 /$ bvhf-e411.

7. World Health Organization. Telemedicine: Opportunities and Developments in Member States: Report on the Second Global Survey on EHealth. World Health Organization;2011.

8. COVID-19 Disrupting Mental Health Services in Most Countries. WHO Survey. Accessed November 11, 2021. Available at: who.int/news/item/05-10-2020-covid19-disrupting-mental-health-services-in-most-countries-who-survey.

9. Bodenheimer TS, Smith MD. Primary care: proposed solutions to the physician shortage without training more physicians. Health Aff. 2013;32(11):1881-1886.

10. Phillips J, Edwards-Johnson J, Wendling A. US federal policies should better support the primary care physician workforce. Fam Med. 2018;50(1):7-9. 


\section{Neurology}

The Collateral Damage of COVID-19

Jonika Tannous and Farhaan S. Vahidy

Neurology 2022;98;219-220

DOI 10.1212/WNL.0000000000013196

\section{This information is current as of February 7, 2022}

\section{Updated Information \&} Services

\section{References}

Subspecialty Collections

Permissions \& Licensing

\section{Reprints}

including high resolution figures, can be found at: http://n.neurology.org/content/98/6/219.full

This article cites 8 articles, 1 of which you can access for free at: http://n.neurology.org/content/98/6/219.full\#ref-list-1

This article, along with others on similar topics, appears in the following collection(s):

All Cerebrovascular disease/Stroke

http://n.neurology.org/cgi/collection/all_cerebrovascular_disease_strok e

COVID-19

http://n.neurology.org/cgi/collection/covid_19

Stroke prevention

http://n.neurology.org/cgi/collection/stroke_prevention

Information about reproducing this article in parts (figures,tables) or in its entirety can be found online at:

http://www.neurology.org/about/about_the_journal\#permissions

Information about ordering reprints can be found online:

http://n.neurology.org/subscribers/advertise

Neurology ${ }^{\circledR}$ is the official journal of the American Academy of Neurology. Published continuously since 1951, it is now a weekly with 48 issues per year. Copyright @ 2022 American Academy of Neurology. All rights reserved. Print ISSN: 0028-3878. Online ISSN: 1526-632X.

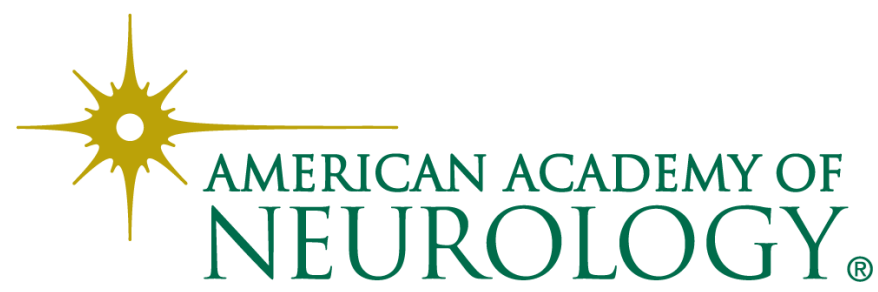

